\title{
LA INFLUENCIA DE LA NARRATIVA DEL SIGLO DE ORO EN LA NOVELA BRITÁNICA DEL XVIII
}

\author{
J. A. G. ARDila \\ Universidad de Extremadura
}

A don Antonio Ardila Traver

El estudio de la génesis y el desarrollo de la novela británica ha sido motivo de discordia para las dos tendencias críticas predominantes que lo han abordado: la tradicional, o masculina, y la feminista. De la primera son abanderados Ian Watt y Walter Allen ${ }^{1}$, quienes aseguran que la novela inglesa surgió, en la primera mitad del siglo XVIII, como culminación de una palingenesia que la prosa experimentara a partir de formas genéricas anteriores. Estos críticos presentan la novela como un género narrativo en prosa, de autoría eminentemente masculina, que tuvo en el realismo formal su característica definitoria y fue estigmatizado por Daniel Defoe, Samuel Richardson, Henry Fielding y Tobias Smollett, a la vez que niegan la categoría de novela a la prosa de autoría femenina anterior a Jane Austen $^{2}$. Por el contrario, los postulados de la crítica feminista comienzan por reclamar el título de primer novelista para Ophra Behn y por vindicar la calidad literaria de más de un centenar de mujeres que publicaron prosa en los siglos XVII y XVIII.

Dos decenios han atestiguado este litigio sin que ninguna de las posturas haya querido dirimir su aparente maniqueísmo; antes mal, la polémica ha impedido cualquier consenso que feche el nacimiento de la novela, identifique a sus precursores y delimite las fronteras entre la novela y el género en prosa anterior, i.e. el romance ${ }^{3}$. De ordinario se aportan nuevas

\footnotetext{
${ }^{1}$ Ian WATT, The Rise of the Novel: Studies in Defoe, Richardson and Fielding (Londres: Chatto, 1957); Walter Allen, The English Novel: a Short Critical History (Harmondsworth: Penguin, 1970).

${ }^{2}$ Prédica que contendiera Dale SPENDER, Mothers of the Novel: One Hundred Good Women Novelists Before Jane Austen (Londres: Pandora, 1987).

${ }^{3}$ En inglés se designa por medio del término romance la prosa anterior a la novela. La historia de la literatura redactada en castellano emplea la expresión novela moderna
} 
perspectivas y osadas teorías que se adscriben a una de las anteriores. En el curso de la pasada década descolló también el estudio de la recepción de la literatura española entre los novelistas británicos del Setecientos -habiéndose considerado fundamentalmente el influjo cervantino, aun si ciertas divagaciones se han centrado también en la novela picaresca y en Celestina- La postura hispánica coincide con la feminista en su oposición a la tradicional, mas es tan desairada por la primera como lo es por la segunda. No obstante, casi un siglo de investigaciones al respecto avalan la determinante influencia de la narrativa del Siglo de Oro español en la novela británica del XVIII, teoría que ha cobrado una reforzada vigencia en el último lustro. El desinterés por el influjo español que tanto la crítica tradicional como la feminista han mostrado es corolario de dos factores: que la casi totalidad de los críticos que antaño reclamaran el influjo hispánico fuesen hispanistas - no réconocidos como peritos en la novela británica- y sus argumentos se aireasen en revistas de filología hispánica; y, como de ello puede inferirse, que muchos británicos y americanos especialistas en novela del XVIII desconociesen la crítica en torno a las novelas cervantina y picaresca. La publicación en 1998 de «Mid-century Quixotism and the Defence of the Novel» de Brean Hammond en la revista Eighteenthcentury Fiction y del libro Don Quixote in England de Ronald Paulson, venerado especialista en literatura y arte británicos del XVIII, ha roto la anterior tendencia, situando la tesis que nos ocupa en el mismo corazón de la crítica angloparlante ${ }^{4}$.

Ciertamente, la influencia que la narrativa española del Siglo de Oro ejerció en la literatura inglesa del XVIII se debe a una variada pléyade de fuentes, mas es, predominantemente, responsabilidad de Cervantes y su Quijote, obra que fascinó así a novelistas de renombre, v.g. Fielding,

donde en inglés se emplea novel. Las veces, los traductores de obras filológicas han preferido no traducir romance, y emplear esta voz como extranjerismo (en cursivas). Sin embargo, la voz castellana romance tiene por tercera acepción en el D.R.A.E. «Novela o libro de caballerías, en prosa o en verso» (acepción que es anterior a la de la estrofa). En «Cervantes y la quixotic fiction: hibridismo genérico», Ardila justifica el uso de la voz castellana romance como equivalente a la cognada inglesa - uso que ha hecho en las publicaciones que se irán citando a lo largo de ésta-. Deyermond y Riley aplican la problemática en torno a la dicotomía romance-novel a la novela española; vid. Alan DEYERMOND, «The Lost Genre of Medieval Spanish Literature», Hispanic Review, 43 (1975), 231-259; Edward C. RILEY, «Cervantes: A Question of Genre», en F. W. HodCROFT et al (ed.), Medieval and Renaissance Studies on Spain and Portugal in Honour of P.E. Russell (Oxford: The Society for the Study of Mediaeval Languages and Literatures, 1981), 69-85. Vid. J.A.G. ARDILA, «Cervantes y la quixotic fiction: el hibridismo genérico», Cervantes, XXI, 2 (2001), 43-66.

${ }^{4}$ Brean HAMMOND, «Mid-century Quixotism and the Defence of the Novel», Eighteenth-century Fiction, X, 3 (1998), 247-268; Ronald PAULSON, Don Quixote in England: The Aesthetics of Laughter (Baltimore: The Johns Hopkins University Press, 1998). 
Smollett, Sterne, Swift o Lennox, como a poetas y pensadores de la talla del tercer conde de Shaftesbury, Addison, Steel o Butler ${ }^{5}$. Hace algo más de un cuarto de siglo, Edwin Knowles aseguraba que: «Along with the Bible, Bunyan, and Shakespeare it [Don Quixote] has been a book that almost every literate English-man for the past two hundred years has read, at least in part» ${ }^{6}$. En 1998 el editor de Don Quixote in England de Paulson anunciaba este volumen proclamando en la contraportada: «Seldom has a single book, much less a translation, so deeply affected English literature as did the translation of Cervantes' Don Quixote in 1612. The comic novel inspired drawings, plays, sermons, and other translations, making the name of the Knight of la Mancha as familiar as any folk character in English lore». Fascinación acerca de la cual Walter Starkie declarara orgulloso: «England is always proud of having been the first foreign nation to recognize the genious of Cervantes» ${ }^{7}$. Y Joseph Jones decía una verdad a medias al proclamar que «Cervantes was Laurence Sterne's favorite author» ${ }^{8}$, puesto que el Quijote fue lectura y modelo predilecto de un buen número de literatos británicos del XVIII - no en vano asevera Britton que «Outside Spain [Don Quixote's] impact has been particularly marked in England, at no point more evidently than during the eighteeth century» ${ }^{9}-$. Los ejemplos de la picaresca alcanzaron también las Islas Británicas y se extendieron por sus bibliotecas en traducciones producidas por un grupo de esforzados hispanistas. Aún hoy se emplean los términos quixotic fiction y picaresque fiction para designar dos corrientes de la novela británica del siglo XVIII, evidencia léxica del impacto que las letras hispanas obraron en los novelistas británicos.

La semántica que a los términos quixotic fiction y picaresque fiction les ha sido impuesta por la crítica angloparlante es la tercera de las rémoras que impiden el reconocimiento del influjo español. La apropiación (o el préstamo indebido) de estos términos filológicos ha contribuido a la

${ }^{5}$ Añádanse las recientes investigaciones que revelan la profunda fascinación con que los artistas británicos del XVIII se inspiraron en el Caballero de la Triste Figura: Rachel SCHMIDT, Critical Images: The Canonization of Don Quixote Through Illustrated Editions of the Eighteenth Century (Londres: McGill-Queen's University Press, 1998); Wendy MотоокA, The Age of Reasons: Quixotism, Sentimentalism, and Political Economy in Eighteenth-century Britain (Londres: Routledge, 1998).

'Edwin B. KNOWLES, «Cervantes and English Literature», en A. Flores y M. J. Benardete (eds.), Cervantes Across the Centuries (Nueva York: Gordian Press, 1969), 277-303, 302.

7 Walter STARKIE, «Miguel de Cervantes and the English Novel», Essays by Diverse Hands, New Series, 34 (1966), 159-179, 166. Antes publicado como «Cervantes y la novela inglesa», en F. SÁNCHEZ CASADO (ed.), Homenaje a Cervantes (Valencia: Mediterráneo, 1950), II, 351-363.

8 Joseph R. JONES, «Two Notes on Sterne: Spanish Sources. The Hinde Tradition», Revue de Littérature Comparée, 46 (1972), 437-444, 437.

9 R. K. BRITTON, «Don Quixote's Fourth Sally: Cervantes and the Eighteenth-Century Novel», New Comparison, 15 (1993), 21-32, 32. 
negación de la influencia española en la novela británica del XVIII: hallar un estudio que reconozca la deuda de los autores británicos con Cervantes es trabajo que entraña no poca dificultad; especialistas en filología inglesa han discutido la influencia de los modelos picarescos españoles sólo para rebatirla y nunca atendiendo a las conclusiones que sobre la picaresca se han alcanzado en el seno de la filología hispánica. El ejemplo más reciente lo constituye Institutions of the English Novel de Homer Brown, donde el autor pretende ilegitimar las teorías de Ian Watt e imponer la hipótesis de que la novela británica no surge hasta la obra de Walter Scott - ya que los ejemplos de Fielding eran ininteligibles para los escoceses y ninguna de las de Defoe o Richardson son «sufficient to represent what later became 'the novel', given not only the radical differences of narrative form and thematic content among them, but also their radically different 'addresses' and levels of social life they 'represented', in all senses of that term» ${ }^{10}$ - A lo largo de su estudio, Brown no hace referencia expresa a la novela picaresca española y sólo dedica dos fugaces alusiones a Cervantes, a quien, además, presenta en su índice onomástico como «Cervantes, S.». Brown no es, empero, sino un ejemplo más, el último, de la remisión de quienes han establecido los parámetros para la comprensión de la novela británica a reconocer el hispanismo de ésta. En este breve ensayo me propongo: (1) señalar los factores literarios e históricos que propiciaron el influjo hispánico en los padres de la novela británica, (2) deslindar las verdaderas dimensiones de dicha influencia - que ya ha desvelado una parte de la crítica- y (3) discutir la semántica de los términos quixotic fiction y picaresque fiction.

Las cinco obras españolas que disfrutaron de una mayor difusión en Gran Bretaña a lo largo de los siglos XVII y XVIII son el Quijote, el Guzmán de Alfarache, la Celestina, el Buscón y el Lazarillo de Tormes. Aunque la primera traducción del Lazarillo al inglés, firmada por David Rowland of Anglesey, data de $1576^{11}$, las traducciones de las tres obras más influyentes no se publicarían hasta el siglo XVII: el Don Quixote de Shelton en 1612; The Rogue, la traducción que James Mabbe hizo del Guzmán, publicada en 1622; y The Spanish Bawd, la traducción de Celestina, rubricada también por Mabbe, de 1631. Guadalupe Martínez Lacalle ${ }^{12}$ ha apuntado

\footnotetext{
${ }^{10}$ Homer Obed Brown, Institutions of the English Novel. From Defoe to Scott (Filadelfia: University of Pennsylvania Press, 1997), ix.

${ }^{11}$ Esta primera traducción fue reimpresa en varias ocasiones. La traducción de la Segunda parte de Lazarillo (1555), de William PHISTON, aparece en 1596 y la anónima de La segunda parte de la vida de Lazarillo de Tormes (1620) de Juan DE MENA en 1622. Para un listado véase Dale B. J. RANDALL, The Golden Tapestry: A Critical Survey of Non-chivalric Spanish Fiction in English Translation (1543-1657) (Durham, N.C.: University of North Carolina Press, 1963), 234-239.

${ }^{12}$ Guadalupe MARTíNeZ LACALle, «An English Hispanist: James Mabbe», en Fernando DE ROJAS, Celestine (Londres: Támesis, 1972), 7-31, 17.
} 
tres razones por las que The Rogue se convirtió en uno de los libros más leídos y reimpresos en la Inglaterra de los Estuardo. En primer lugar el tipo de aventuras que corre el pícaro sevillano no eran completamente desconocidas para el lector británico, ya que desde hacía aproximadamente un siglo se había publicado en Gran Bretaña un tipo de relatos conocidos como beggar-books o literature of the low life que narraban las andanzas de personajes de corte picaresco ${ }^{13}$. Lacalle resalta también la simpleza de la literatura británica de la época, y sugiere que tanto lectores como literatos encontraron en las ingeniosas andazas de Guzmán una fuente de entretenimiento así como un modelo literario en que inspirarse. Por último repara Lacalle en las excelentes relaciones políticas que por entonces mantenían Gran Bretaña y España, desde que la Infanta María se prometiese en matrimonio a Carlos, Príncipe de Gales ${ }^{14}$. Estas tres razones pueden aplicarse también al éxito de The Spanish Bawd y de Don Quixote en el siglo XVII. A los puntos que propone Lacalle han de añadirse la extraordinaria calidad literaria de estos textos, que han contribuido a definir un siglo de oro, así como la excelencia de las traducciones, muy especialmente las de Mabbe ${ }^{15}$, que han pervivido a lo largo de los siglos en las preferencias del mercado editorial ${ }^{16}$.

${ }^{13}$ Como por ejemplo The Fraternity of Vagabondes (1565) de John Awedeley, además de las obras de Robert Green, Thomas Middleton o Thomas Nashe. Vid. Arthur F. KINNEY (ed.), Rogues, vagabunds, \& sturdy beggars: a new gallery of Tudor and Early Stuart rogue literature (Amherst: University of Massachusetts Press, 1990) y Gamini SALGADO, The Elizabethan Underworld (Londres: Dent, 1977).

${ }^{14}$ Relaciones que se habían deteriorado desde el divorcio de Enrique VIII y Catalina de Aragón en 1533, cuyo matrimonio selló la relación de sangre entre la casa real inglesa e Isabel la Católica, tataranieta de John de Gaunt, Duque de Lancaster, y que se hicieron hosca hostilidad tras el ascenso al trono de la protestante Isabel I (hija de Ana Bolena y Enrique VIII), a costa del derrocamiento de la católica María (hija de Catalina y Enrique, y esposa de Felipe II). Sobre Catalina de Aragón véase David STARKEY, Six Wives: The Queens of Henry VIII (Londres: Chatto \& Windus, 2001), estudio serializado para el Channel 4 británico bajo el título The Six Wives of Henry VIII (emitidos a partir del 13 de septiembre de 2001) y resumido en dos suplementos para The Sunday Telegraph (3 y 9 de septiembre de 2001). Sobre las tensiones diplomáticas entre España e Inglaterra en el reinado de Isabel I véase Paul C. Allen, Phillip III and the Pax Hispanica, 15981621: The Failure of Grand Strategy (New Haven y Londres: Yale University Press, 2000).

15 Vid. P. E. RuSSELl, «A Stuart Hispanist: James Mabbe», Bulletin of Hispanic Studies, XXX (1953), 75-84; Guadalupe MARTÍNEZ LACALLE (op. cit.).

${ }^{16}$ Aún en 1986, Dorothy S. SEvERIN prefería la traducción de Mabbe para su edición bilingüe de Celestina (Warminister: Aris \& Philips, 1986), a pesar de disponer de las de Lesley Byrd SIMPSON (Berkeley y Los Angeles: University of Califonia Press, 1955), M.H. Singleton (Madison: University of Wisconsin Press, 1958), Phyllis HARTNOLL (Londres: University of London, 1959) y J.M. COHEN (Harmondsworth: Penguin, 1964). Las traduciones del XVII y del XVIII corresponden a Johns STEPHENS (1707) y el Capitán John STEVEns (1707). Las ediciones de la traducción de Mabbe incluyen la de James FitZMAuricE-Kelly de 1894 (Londres: Nutt) y las de H.W. Allen de 1908 (Londres: Routledge) y 1959 (Londres: Dent). 
En los primeros lustros del siglo XVIII surgió un nuevo y acentuado interés por la literatura española que se debió a motivos de diferente índole. Los autores británicos seguían huérfanos de modelos de autoridad imperecedera e inspiradora. Sin embargo, las relaciones políticas entre Inglaterra y España se habían deteriorado hasta resucitar el antiguo odio de tiempos de María Tudor e Isabel $\mathrm{I}^{17}$. El objeto de las disputas entre los gobiernos inglés y español no era ya tanto la religión como la pugna por el dominio de las rutas comerciales de ultramar. El primer conflicto armado, en el XVIII, entre estas dos potencias se declara en 1702; inmediatamente después, en 1704, Gran Bretaña gana Gibraltar. El tratado anglo-hispánico de 1713 permitía a los británicos controlar el mercado de esclavos español y el comercio de productos europeos con Hispanoamérica. En 1718 se desencadena una segunda guerra entre Inglaterra y España, y en 1739 estalla una tercera, alentada por las multitudinarias manifestaciones hispanófobas promovidas por el Príncipe de Gales y celebradas en 1738 y 1739 . La Guerra de Sucesión española permitió a Inglaterra enviar en 1740 sus ejércitos contra los españoles. En definitiva, se puede afirmar que durante la primera mitad del siglo XVIII España e Inglaterra vivieron una constante confrontación política y armada. Resulta imposible, por todo lo anterior, entender la política internacional como un factor que favorecise la incursión de la literatura española en Gran Bretaña.

Las causas que provocaron la admiración por los clásicos españoles fueron de tipo literario y social. Entre las literarias se cuentan (1) la dicotomía novela-romance y (2) la ya mentada calidad de los ejemplos españoles. Las históricas son (1) el aumento de la delincuencia, (2) de la demografía y (3) de los centros urbanos, (4) el desarrollo del turnpyke road system, (5) el nacimiento del imperio y (6) los intereses políticos que alentaban la crítica social.

Tanto la novela picaresca como el Quijote representan en la literatura española el paso del romance a la novela. (La prosa del romance se caracterizaba por su idealismo, y la de la novela por su realismo formal). Esta palingenesia se obra en la novela picaresca ${ }^{18}$; sin embargo, es Cervantes

\footnotetext{
17 A pesar de que Nicholas Round («What Made Mabbe So Good?», Bulletin of Hispanic Studies, Glasgow, LXXVIII, 1 [2001], 145-166) haya reprochado a ARDILA el uso de fuentes decimonónicas a fin de ejemplificar la política inglesa del XVII en «Una traducción políticamente correcta: Celestina en la Inglaterra puritana» (Celestinesca, XX, 2 [1998], 33-48), François GuIzoT (Historia de la revolución de Inglaterra [Madrid: Sarpe, 1985]) continúa siendo un clásico del estudio de la época en cuestión, aún no rebatido (como demuestra su reimpresión a finales del XX), en que se señalan las tensiones entre las coronas inglesa y española. Véase, asimismo, el volúmen de Gustav UNGERER, Anglo-Spanish Relations in Tudor Literature (Berna: Francke Berlag, 1956), que también se cita en «Celestina en la Inglaterra puritana» y que parece haber pasado inadvertido al escrutar de Round.

${ }^{18}$ Entre los estudios más recientes, véase Fernando CABo AsEnguinola, El concepto de género y la literatura picaresca (Santiago de Compostela: Universidad de Santiago, 1992).
} 
quien denuncia de modo más explícito lo absurdo del idealismo de los romances en grado que se proclame la urgente necesidad que la literatura tenía de superar este género ${ }^{19}$. La prosa inglesa de principios del XVIII se hallaba dominada por el romance. A finales del siglo XVII se había producido un significativo auge de la prosa de autoría femenina, pero las obras de estas escritoras continuaban adoleciendo de un idealismo y un irrealismo que les valió la censura de los intelectuales. La primera novela británica es aquella narración que, por primera vez, fluye por los cauces del realismo formal, esto es, cualquiera de las firmadas por Daniel Defoe o, en su defecto, Pamela de Richardson. No obstante, los esfuerzos por fijar un canon y las elucubraciones en torno a la tipología genérica de la novela se prosiguieron hasta la segunda mitad del siglo. En su esfuerzo consciente por fijar las fronteras genéricas de la novela y distinguirla de los romances, quienes aspiraban a ser llamados los padres de la novela inglesa se fijaron en el novelista y la novela que habían logrado esos mismos objetivos hacía más de un siglo, esto es, en Cervantes y el Quijote. Durante las últimas décadas del siglo XVII, la literatura inglesa sólo había ofrecido a sus lectores obras de un tedioso tono puritano y plúmbeos tratados filosóficos e históricos. Gran Bretaña apreció sin reparos el humor, la crítica social, la sátira, las dimensiones ontológicas y las técnicas narratológicas que eran endémicas a la novela picaresca y al Quijote. Tal reconocimiento coincidió, asimismo, con la unánime aceptación de modelos artísticos provenientes del continente. (El reconocimiento de los cánones artísticos europeos se puede apreciar en pintores de ese siglo, como Joseph Wright of Derby).

No menos significativas son las circunstancias históricas que Gran Bretaña vivía en el siglo XVIII y que alentaron el interés por los pícaros y la vida picaresca, que ya habían propiciado los beggar-books. En primer lugar hay que reparar en el agudo crecimiento físico de las ciudades ${ }^{20}$, corolario de la revolución industrial en ebullición ${ }^{21}$ y del afianzamiento de la clase burguesa, cuya principal actividad era el comercio ${ }^{22}$. En esos años, la vida urbana en Inglaterra se debatía en un extraño marco en que se confundían pobreza y bonanza. La especulación en los años veinte, añadi-

${ }^{19}$ En efecto, el Quijote se ha entendido como producto de la evolución del idealismo al realismo, véase, por ejemplo, Edward C. RILEY, Teoría de la novela en Cervantes (Madrid: Taurus, 1981), 529-290; Edwin WILliamson, El Quijote y los libros de caballerías (Madrid: Taurus, 1991), 58. Cf. Mark SinglETON, «The Persiles mystery» en A. Flores y M. J. BenARDETE, op. cit., y Ruth El SAFFAR, Novel to Romance: A Study of Cervantes Novelas Ejemplares (Baltimore y Londres: The Johns Hopkins University Press, 1974).

${ }^{20}$ Vid. P. CORNFIELD, The Impact of English Towns 1700-1800 (Oxford, 1982).

${ }^{21}$ Vid. E. Pawson, The Early Industrial Revolution: Britain in the Eighteenth Century (Londres, 1979).

22 Vid. R. POTER, English Society in the Eighteenth Century (Londres, 1982). 
da a la deuda exterior (o National Debt), produjo una verdadera catástrofe semejante a las que también azotaban París y Amsterdam. En los años treinta y cuarenta, el desempleo en las regiones industrializadas, en especial las áreas textiles, se había convertido en un grave problema social. Por otro lado, la inflación era casi inexistente y resultaba posible adquirir todo tipo de bienes a precios razonablemente asequibles. Por esta razón, la demanda de productos se multiplica y florecen las industrias y el comercio: se exploran rutas comerciales; se incrementa el comercio, especialmente con las colonias norteamericanas, y se trata de controlar las rutas españolas ${ }^{23}$. (El de Birmingham es un ilustrativo ejemplo del inusitado crecimiento físico y demográfico de las ciudades: la industria de Birmingham se especializó en la fabricación de utensilios domésticos que se conocían como Birmingham goods y cuya alta calidad y bajos precios los hicieron harto populares en toda Gran Bretaña). Como en cualquier revolución industrial, las clases más humildes acuden a las ciudades en busca de trabajo, produciendo esta masificación humana altas cotas de desempleo. La situación social se agravó debido a los nuevos impuestos fijados en grado que se recuperasen las reservas nacionales, mermadas a causa de las guerras, que a principio de siglo habían costado ya 150 millones de libras esterlinas de la época ${ }^{24}$. El resultado de todo lo anterior es la convivencia en grandes núcleos urbanos de la clase pudiente con las más desfavorecidas, a la vez que la pirámide social experimenta un sorprendente estiramiento ${ }^{25}$.

A las diferencias sociales contribuyó notablemente la inusitada revolución demográfica. Si bien las epidemias de 1727 habían causado una notable recesión en los índices de natalidad durante el reinado de Jorge III, precipitándose a porcentajes tan bajos como los registrados en el siglo XVI, la década de los treinta experimentó un asombroso crecimiento demográfico. Se estima que la población en 1750 debía de ser de unos 5.8 millones de habitantes; en 1770, de algo más de seis, y en 1790, de ocho. El incremento de la población tuvo como consecuencia inmediata el aumento del desempleo: primero en zonas rurales, de donde los más desfavorecidos emigran a las ciudades en busca de trabajo en la industria, que ya no precisa de ellos, optando entonces por permanecer en las urbes. Las alarmantes

${ }^{23}$ Vid. N. MCKendrick, J. Brewer y J. H. Plumb, The Birth of a Consumer Society: The Commercialization of Eighteenth-century England (Londres, 1982).

${ }^{24}$ David Blewett sugiere que las cantidades del XVIII se multipliquen por sesenta para hallar un equivalente aproximado al valor de la moneda a finales del XX. David BLEWETT, «A Note on Currency», en Daniel DEFOE, Moll Flanders (Harmondsworth: Penguin Classics, 1989), 27-28.

${ }_{25}$ Vid. G. E. MINGAY, English Landed Society in the Eighteenth Century (Londres, 1963), R. W. MALCOLMSON, Life and Labour in England 1700-1780 (Londres, 1981), J. CAnnon, Aristocratic Century: The Peerage of Eighteenth-century England (Cambridge, 1984). 
cifras de desempleo fueron las responsables del auge de la delincuencia y el crimen ${ }^{26}$. El cenobio de opulencia y miseria sirvió a muchos para justificar la práctica del hurto como negocio que las injusticias sociales hacían lícito. El robo por medio de zalagardas, practicado al albur de la confusión de las tumultuosas ciudades ${ }^{27}$, resultaba más rentable que el crimen y fue animado por los muchos escándalos protagonizados por personajes ilustres que empleaban sus cargos para enriquecerse ilícitamente, v.g. el de los trustees de Derwentwater, el de los directivos de la Charitable Corporation, que implicó a varios Members of Parliament (o diputados), el del Lord Chancellor Lord Macclesfield, destituido bajo acusación de practicar una administración corrupta.

Antes de la década de los veinte, el trazado de las carreteras que recorrían Gran Bretaña era muy limitado: la principal de las rutas que partía de Londres hacia el norte, la conocida como Great North Road, no llegaba a Birmingham; y la Great West Road apenas alcanzaba Oxford. Además de ser inseguras, el tránsito privado por estas carreteras importaba un elevado coste, ya que las rutas dependían de las parroquias por las que discurrían, y éstas habían impuesto un sistema de peaje. En 1741, por el contrario, el nuevo turnpike road system permitía al viajero desplazarse desde Canterbury hasta Manchester o Bristol por la misma turnpike road libre de peajes. En 1770 las turnpike roads alcanzaban pequeñas poblaciones en los más recónditos rincones de Inglaterra. En el periodo comprendido entre 1720 y 1780 la mejora de los transportes es sorprendente, resultando posible viajar de modo más barato, seguro y, sobre todo, rápido: desplazarse a York desde Londres requería tres días en los años veinte, frente a las no más de veinticuatro horas en los ochenta.

De tal suerte, el viaje se convierte en una de las aficiones nacionales. La mejora de las rutas y la pública exención de peajes invita a las clases más pudientes a desplazarse asiduamente a Bath, a los pobres a recorrer ciudades en busca de empleo, a los empresarios a abrir posadas en las carreteras, etc. De este modo, el viaje se toma como uno de los motivos argumentales más recurridos en la prosa del momento (y los libros de viajes acaparan una parte importante del mercado editorial), v.g. en Joseph Andrews y Tom Jones de Henry Fielding, en Roderick Random y Humphry

${ }^{26}$ Vid. D. HAY, P. Linebaugh y E. P. Thompson, Albion's fatal Tree: Crime and Society in Eighteenth-century England (Londres, 1979); J. M. BEATTIE, Crime and the Courts in England 1660-1800 (Oxford, 1986).

${ }^{27}$ Sobre todo en Londres. Vid. M. D. GEORGE, London Life in the Eighteenth Century (Londres, 1925), texto ya clásico. Análisis más recientes se encuentran en: Maureen WALLER, 1700: Scenes from London Life (Londres: Hodder and Stoughton, 2001); Liza PICARD, Dr Johnson's London (Londres: Weidenfeld and Nicolson, 2000); Peter ACKROYD, London: A Biography (Londres, 2000); Roy PORTER, London: A Social History (Londres, 1994); Stephen INwood, A History of London (Londres, 1998). 
Clinker de Smollett o en A Sentimental Journey de Sterne. Si Defoe, en 1722, narra cómo Moll Flanders se desplaza de Londres a Lancashire, Henry Fielding pone a todos los personajes de su Tom Jones (1748) en las carreteras que cruzan Inglaterra desde Somersetshire a Londres. Los caminos se convierten en uno de los escenarios principales de la novela y la acción narra una sucesión de aventuras y un constante devenir de personajes secundarios.

La primera mitad del siglo XVIII ha servido a los historiadores para fechar el comienzo de la hegemonía británica en ultramar. Tras la firma del tratado de Utrecht en 1713, la marina británica pasa a imponer su supremacía naval en los siete mares - principalmente en detrimento de los intereses españoles-, que se demostraría por medio de las victorias logradas en la Guerra de Sucesión española, con las de Marlborough en Blenheim y Ramillies, la de Rooke en Gibraltar y la de Stanhope en Menorca. A partir de entonces, la historia llama Imperio a Gran Bretaña, que alcanza supremacía mundial durante el reinado de la reina Victoria - prolijo en las artes ${ }^{28}$ - La bonanza imperial agudiza las tensiones sociales que la estirada pirámide social había engendrado: mientras que la clase burguesa encuentra en la hegemonía mundial británica una nueva vía para la productividad de su riqueza, las clases más humildes asisten impotentes al realzamiento del nombre de su país sin poder dirimir sus privaciones. Esta desigualdad tizna las miserias de ese imprevisto excedente demográfico, que adquieren un dramatismo y una crueldad tan irónicas como paradójicas. (Daniel Defoe presenta en sus novelas las vidas de muchos de estos desheredados a quienes el imperio británico no aportó beneficio alguno). El nacimiento del imperio amplía los horizontes del viajero y el aventurero: las novelas de la época no se reducen a las excursiones a Bath, sino que se extienden a las colonias de ultramar e incluso a reinos desconocidos, como en los Gulliver's Travels. Las provincias de allende los mares sirven como escenario a aventuras de toda índole de personajes: aventureros, viajeros, militares y criminales y cacos que a menudo eran sentenciados al destierro en los penales de Virginia.

Mas las divisiones sociales proliferaron e hicieron de Gran Bretaña un crisol de grupos sociales y étnicos y de posiciones encontradas, en especial en lo referente a la tensión política entre Tories y Whigs, enardecida por las pretensiones de los Cavaliers, grupo partidario de los Estuardo y enemigo de la reinante casa de Hanover. Los conceptos de nación se con-

\footnotetext{
${ }^{28}$ Además de la literatura, con Dickens, Thackeray, Las Brotës, George Eliot, George Meredith, Robert Browning, los Rossetti y un largo etcétera, las escuelas musicales y pictóricas británicas producen dos de sus corrientes más celebradas: la escuela pastoral en música, sobre todo con Edward Elgar, y con Ralph Vaughan Williams, Percy Grainger y Frederick Delius a principios del siglo Xx; y la Hermandad Prerrafaelita de Dante Gabriel Rossetti, Burne-Jones, Hunt o Millais.
} 
funden. Los Cavaliers habían permanecido en Francia durante el destierro a que los empujó la república puritana, y sus intereses católicos no toleraban el marcado protestantismo de los Hanover; en 1707, el parlamento escocés es suprimido y los católicos escoceses ven en las reivindicaciones jacobitas la oportunidad de reafirmar su nacionalismo frente al poderío inglés que entienden que es su principal enemigo desde Eduardo I Plantagenet (1272-1307). Las tensiones se suceden hasta la estrepitosa derrota de los clanes escoceses en la batalla de Culloden, en 1746, con que exasperan las pretensiones jacobitas. A la división religiosa debe añadirse la existencia de una descontenta minoría judía, contra la cual se expidió la Jew Bill de 1753, redactada por Pelham. Las fricciones entre grupos religiosos permiten que florezca la literatura de tono burlesco e irónico. La crítica social se desarrolla fundamentalmente en torno a la corrupción de las ciudades: a la sátira y la ironía implícita en Beggar's Opera de John Gay, Dunciad de Pope, Gulliver's Travels de Swift y Bolinbroke de Craftman se unirían los novelistas más representativos del momento, como Fielding y Smollett.

Tanto los condicionantes literarios como aquellos de carácter histórico en que se encuadran las primeras décadas de la novela británica se corresponden con las situaciones histórica y literaria de la España del Siglo de Oro $^{29}$. En España, la dicotomía romance-novela encuentra uno de sus más expresivos debates en la discusión que el canónigo de Toledo y el cura mantienen con Don Quijote. En Inglaterra, Henry Fielding dedica el Preface de su Joseph Andrews o ciertos capítulos de Tom Jones a menoscabar con acento diletante el mérito artístico del romance, ensalzar lo apropiado de la novela en el macronivel de las artes y - como ya hiciera Cervantesblasonar de ser el primero en novelar en su lengua. Tobias Smollett expone en el «Preface» de su primera novela, Roderick Random, una serie de disquisiciones acerca de la necesidad de dejar atrás el romance y considerar la novela como el nuevo género en prosa ${ }^{30}$. La España de finales del XVI y principios del XVII sufrió también un aumento de la delincuencia y el crimen organizado, sus ciudades acogieron oleadas de inmigrantes procedentes de las zonas rurales, su enclave geográfico facilitó la apertura de rutas marítimas, nació entonces el imperio, mientras la sociedad se escindía en clases sociales y adolecía de una dolorosa carestía de unidad reli-

\footnotetext{
${ }^{29}$ Cf. J. A. G. ARDILA, «La tradición picaresca española en Inglaterra», Bulletin of Hispanic Studies, Liverpool, LXXVI, 4 (1999), 453-469, 453-454.

${ }^{30} \mathrm{Si}$ bien la crítica se esmeró en debatir la calidad picaresca de Roderick Random, J. A. G. Ardila ha demostrado cómo Smollett procuró diseñar en esta obra una novela al modo que Cervantes hiciese en el Quijote, i.e. estableciendo una diferenciación entre la novela y el romance. Además de las divagaciones genéricas que se contienen en el «Prologue», Ardila observa también características propias de la novela cervantina - situaciones y figuras retóricas-. Vid. J. A. G. ARDILA, «La teoría cervantina de la novela en Roderick Random», Bulletin of Spanish Studies, LXXIX (2002), en prensa.
} 
giosa. Los novelistas británicos hallaron en las novelas picarescas españolas, sobre todo en el Guzmán, una prosa de realismo y calidad, preocupada por el aumento de la clase delincuente que sobrevivía arduamente en la opulencia de las ciudades, sabía desplazarse por el territorio nacional, por otros países europeos y por las colonias ultramarinas. Las aventuras de Lázaro, Guzmán o Pablos atraen de inmediato la atención de los novelistas ingleses, quienes vislumbran en estas narraciones españolas un marco análogo al de la sociedad que ansían retratar con un realismo propio de la novela (e impropio del romance). Las similitudes entre los viajes de los pícaros españoles y los protagonistas de las novelas británicas son evidentes, véase el discurrir de los viajes de Tom Jones y los de Pablos, y en cómo los episodios son de la misma factura cómica, descriptiva e, incluso, temporal: el episodio (VII, 10), en que Tom se cree perdido en su viaje a Bristol, y la conversación que mantiene con un oriundo tras preguntarle el camino es de reminiscencias quevedianas, en concreto del diálogo entre Pablos y el matemático ${ }^{31}$. La pervivencia en la España del XVII de varios credos religiosos y el compromiso que la novela adquirió con las problemáticas sociales en torno al sometimiento de una minoría étnica así como la crítica a la corrupción captaron también la atención de los novelistas británicos. Las similitudes entre la España del Siglo de Oro y la Gran Bretaña del XVIII propiciaron que los británicos leyesen con interés y admiración la literatura española (que había propendido a reflejar esos mismos condicionantes sociales) y que, en muchas ocasiones, modelasen sus obras con arreglo a los cánones españoles.

Cervantes despertó una admiración por las letras castellanas sin precedentes y abrió las puertas de Inglaterra, entonces inexpugnable enemiga de todo lo hispánico, a la narrativa del Siglo de Oro. En efecto, desde que los pictos alcanzaran las Islas Británicas antes que los celtas, Inglaterra repudió casi todos los embistes políticos y marciales de España. Desde la inclusión de Juan Vives en el círculo intelectual de Tomás Moro (1523), el matrimonio de Catalina de Aragón con Arturo Príncipe de Galés (1501) y el de Felipe II con María Tudor (1554), ningún español de renombre habían sido bienvenido en Inglaterra. La influencia de Cervantes es anterior a la ejercida por Alemán y, como apuntaré más adelante, condicionó la que ejerciese Celestina. La presencia de Cervantes en las letras inglesas, como autor de Don Quixote y las Exemplary Novels, ha ocupado el interés de la filología desde que James Fitzmaurice-Kelly y Gustav Becker publicaran sendos estudios a principios del siglo $\mathrm{XX}^{32}$. El cervantismo de

${ }^{31}$ Fielding tembién se refiere en Tom Jones a Quevedo (VII, 8): «... For I would not, like the old woman in Quevedo, injure the Devil by any false accusation...».

32 James FitZMAurice-Kelly, «Cervantes in England», Proceedings of the British Academy, III (1905-06), 11-30; Gustav BECKER, Die Aufnahme des Don Quijote in die englische Litteratur (1605-c.1770) (Berlin, 1906). 
la novela británica ha engendrado numerosos ensayos de carácter crítico y comparativista ${ }^{33}$; sin embargo, incido en ello, la influencia de Cervantes ha sido ignorada por las figuras más destacadas de la crítica angloparlante. Ejemplos de ello son los volúmenes considerados imprescindibles para la comprensión del periodo, como los de Ian Watt y Walter Allen y otros tan recientes como (el ya citado) Institutions of the English Novel de Brown y The Eighteenth Century: The Intellectual and Cultural Context of English Literature 1700-1789 de James Sambrook ${ }^{34}$. La rama feminista de la crítica, más preocupada por denostar las tesis tradicionales y ensalzar la labor de las mujeres en la fragua de la novela como género, ha pasado por alto a Cervantes y su Quijote. Sólo un reducido grupo de especialistas en el periodo, como Jill Campbell, S. Gilman, Aurelien Digeon, Ernest Baker, Martin Battestin o, más recientemente, Clive Probyn, Walter Reed y Michael McKeon ${ }^{35}$, quien incluso dedica un 'capítulo de su Origins of the Novel a Cervantes, han reconocido la presencia hispánica. En lo concerniente a la didáctica, cabe reseñar cómo las depuradas antologías escritas para grandes casas editoriales eluden cualquier discusión en torno a la influencia cervantina. La Short Oxford History of English Literature ${ }^{36}$ no presta mayor atención a Cervantes y el Quijote que la que brinda a otros escritores

${ }^{33}$ Entre los ensayos más influentes hasta los años noventa se cuentan: Miriam $R$. SMALL, «The Female Quixote and Other Quixotic Imitations of the Eighteenth Century», en Charlotte Ramsey Lennox. An Eighteenth-century Lady of Letters (New Haven: Yale University Press, 1935), 64-117; E. ALLISON PEERS, «Cervantes in England», Bulletin of Spanish Studies, XXV (1947), 226-238; Alexander A. PARKER, «Fielding and the Structure of Don Quixote», Bulletin of Hispanic Studies, XXXIII (1959), 1-16; Susan STAVES, «Don Quixote in Eighteenth-century England», Comparative Literature, XXIV (1972), 193-215; Edward L. NIEHUS, "Quixotic Figures in the Novels of Sterne», Essays in Literature, 12 (1985), 41-60; Juan Bautista AVALLE-ARCE, «Quijotes y quijotismos del inglés», Ojáncano, 2 (1989), 58-66.

${ }^{34}$ James SAMBRoOK, The Eighteenth Century: The Intellectual and Cultural Context of English Literature 1700-1789 (Londres: Longman, 1993).

35 Jill CAMPBELL, Natural Masks: Gender and Identity in Fielding's Plays and Novels (Stanford: Stanford University Press, 1995), 96; S. GILMAN, «On Henry Fielding's Reception of Don Quixote», en R. A. CARDWEll y I. MiChaEl (eds.), Medieval and Renaissance Studies in Honour of Robert Brian Tate (Oxford: Dolphin, 1986), 27-38; Aurelien DigEON, The Novels of Fielding (Nueva York: Russell \& Russell, 1925), 64; Ernest BAKER, The History of the English Novel (Nueva York: Barnes \& Noble, 1936), IV, 93; Martin BATTESTIN, The Moral Basis of Fielding's Art (Middleton: Wesleyan University Press, 1959), 86; Martin BATTESTIN, A Henry Fielding Companion (Westport y Londres: Greenwood Press, 2000), 71; Clive ProByn, English Fiction of the Eighteenth Century 1700-1789 (Londres: Longman, 1987), 108-111; Walter REED, An Exemplary History of the Novel: The Quixotic versus the Picaresque (Chicago: Chicago University Press, 1981); Michael MCKEON, The Origins of the English Novel, 1600-1740 (Baltimore: The Johns Hopkins University Press, 1987).

36 Andrew SANDERS, The Short Oxford History of English Literature (Oxford: Clarendon Press, 1996), 255, 312. 
extranjeros: nombra el Quijote como prosapia de Hudibras, empero, más lejana que Rabelais, y en un listado de autores que inspiraron a Fielding, sin querer determinar su importancia. Las más modernas ediciones de las obras de Fielding, Smollett o Sterne tampoco confieren demasiada importancia a Cervantes: Brisseden apenas apunta que «Joseph Andrews, Fielding tells us on the title page, is 'Written in Imitation of the Manner of Cervantes, Author of Don Quixote', and Don Quixote certainly undergoes a transformation of this short [romance to novel]» ${ }^{37}$; Mutter sólo admite del cervantismo de Tom Jones que Partridge «is a thin shadow of Sancho Panza» ${ }^{38}$; Melvyn New apenas menciona a Cervantes y el Quijote en un listado de influencias de Sterne ${ }^{39}$; y, en su introducción a Humphry Clinker, Angus Ross sólo menciona el Don Quixote de Smollett para equiparar la calidad artística del original a la novela de que es objeto su ensayo ${ }^{40}$. Revisiones críticas de este jaez explican que el lector angloparlante, especializado o profano, quede convencido que Cervantes no pasó de ser una trivial referencia en la novela británica, de trascendencia menor, incluso, a la que ejercieron Rabelais, Montagne u Horacio, y sin saber exactamente en qué forma Joseph Andrews fue escrito como imitación del Quijote.

Coincidiendo con el auge de la crítica feminista, algunas se obcecaron en pretender demostrar denodadamente que las pocas novelas que habían sido reconocidas como imitations del Quijote eran en realidad prosa de impronta feminista. El primero de estos argumentos lo firmó Elaine Kau$\operatorname{var}^{41}$, quien declaró que el cervantismo hasta entonces atribuido por historiadores de la literatura al tono paródico de Northanger Abbey de Jane Austen respondía en realidad a la admiración que esta autora profesaba a The Female Quixote de Charlotte Lennox. A finales de los ochenta, Margaret Doody, paladín de la teoría feminista de que no existió diferencia alguna entre romance y novela ${ }^{42}$, restringe la influencia cervantina en la novela de Lennox al mero préstamo del título. Doody afirma que Cervantes jamás trató de parodiar los romances ${ }^{43}$ - sin ofrecer una revi-

${ }^{37}$ R. F. BRISSEDEN, «Introduction», en Henry FIELDING, Joseph Andrews (Harmondsworth: Penguin Classics, 1985), 8.

${ }^{38}$ R. P. C. MUTTER, «Introduction», en Henry Fielding, Tom Jones (Harmondsworth: Penguin Classics, 1985), xxvi.

${ }_{39}$ Melvyn NEw, «Editor's Introduction», en Laurence STERnE, The Life and Opinions of Tristram Shandy, Gentleman (Harmondsworth: Penguin Classics, 1997), xxxiii, xxxix.

${ }^{40}$ Angus Ross, «Introduction», en Tobias SMOLLETT, Humphry Clinker (Harmondsworth: Penguin Classics, 1985), 10, 19.

${ }^{41}$ Elaine M. KaUVAR, «Jane Austen and The Female Quixote», Studies in the Novel, 2 (1970), 211-221.

${ }^{42}$ Margaret Anne Doody, The True Story of the Novel (New Brunswick: Rutgers Univesity Press, 1996).

${ }^{43}$ Margaret Ann Doody, «Introduction», en Charlotte LENNox, The Female Quixote (Oxford: Oxford University Press, 1989), xiv. 
sión de la investigación cervantista que así lo ha estimado y sin aclarar tampoco cuál fue el objeto, a su parecer, del Quijote - y vindica el feminismo de la producción literaria de Lennox.

La perspectiva crítica ha cambiado sustancialmente en los últimos cinco años. Siquiera algunos porfíen en obstar el cervantismo que impregnó la novela británica del Setecientos, la publicación de estudios que demuestran fehacientemente lo contrario ha sido prolija en los últimos años. Pardo García ${ }^{44}$ ha repasado las evidencias del quijotismo de Joseph Andrews y argumentado que la influencia cervantina en la obra de Laurence Sterne fue ubicua; asimismo, ha sabido incluir a Samuel Richardson en «a narrative tradition especially fruitful in $18^{\text {th }}$-century English fiction» que toma como referencia una «dialogical form by incorporating the discarded romance world-view as one of the main participants in the dialogue of world-views, by making the confrontation between romance idealism and debased realism the basis of a dialogue, by investigating the romantic imagination separated from the world» ${ }^{45}$. Pardo García ofrece asimismo un cuidadoso análisis del dialogismo bajtiniano en Tom Jones y Humphry Clinker, reclamando ésta como característica cervantina ${ }^{46}$.

Por su parte, J.A.G. Ardila ${ }^{47}$ ha contradicho las prédicas feministas de Kauvar y de Doody con respecto a The Female Quixote y Northanger Abbey, probando que el tono paródico de estas dos novelas es genuinamente cervantino. Aparte de la anterior aportación al recurrido análisis de la parodia de géneros, Ardila ha investigado asimismo las propiedades narratológicas de novelas paradigmáticas en el desarrollo del género en Gran Bretaña. Ardila retoma la cuestión del cervantismo del principal ejemplo de la novelística de Fielding, Tom Jones - negada por toda la crítica angloparlante y apuntada sólo por Alexander Parker y Pardo García ${ }^{48}$-, y demuestra analogías entre el Quijote y Tom Jones en la casi totalidad de los recursos narratológicos ${ }^{49}$. También ha emparentado Ardila el Quijote

${ }^{44}$ Pedro Javier PARDo GARCía, La tradición cervantina en la novela inglesa del siglo XVIII (Salamanca: Ediciones Universidad de Salamanca, 1997) y «Formas de imitación del Quijote en la novela iglesa del siglo XVIII: Joseph Andrews y Tristram Shandy», Anales Cervantinos, XXXIII, (1995-97), 133-164.

${ }^{45}$ Pedro Javier PARDo GARCÍA, «Novel, Romance and Quixotism in Richardson's $\mathrm{Pa}$ mela», Atlantis, XVIII, 1-2 (1996), 306-336, 334.

${ }^{46}$ Pedro Javier PARdo GARCía, « La otra cara de Cervantes en la novela inglesa del siglo XVIII: Tom Jones y Humphry Clinker», Actas del II Congreso Internacional de la Asociación de Cervantistas (Nápoles: Instituto Universitario Orientale, 1995), 839-854.

47 J. A. G. ARDILA, «Cervantes y la quixotic fiction: la parodia de géneros», Anales Cervantinos, XXXIV (1998), 145-168.

${ }^{48}$ Alexander PARKer, op. cit.; Pedro Javier PARdo GARCía, «La otra cara de Cervantes en la novela inglesa del siglo XVIII: Tom Jones y Humphry Clinker» (op. cit.).

49 J. A. G. ARDILA, «Cervantes y la quixotic fiction: sucesión episódica y otros recursos narrativos», Cervantes, XXI, 1 (2001), 43-65. 
con la novela de Tobias Smollett predilecta a los ojos de la crítica, i.e. Humphry Clinker. La lectura del análisis de Ardila evidencia que Tobias Smollett, traductor del Quijote y uno de los novelistas de más excelsa fama en el XVIII, se basa en el hibridismo genérico propio de la novela de Cervantes para elaborar una prosa genuinamente novelística, redactando lo que la crítica literaria ha denominado después hipertexto o antiroman ${ }^{50}$.

Brean Hammond ha preferido reclamar el cervantismo de la totalidad de los novelistas de renombre que dio la Gran Bretaña del XVIII. Hammond afirma que la influencia cervantina alcanzó de lleno las obras de Smollett y Sterne, que Fielding estableció diferencias con respecto a Richardson siguiendo los cánones paródicos de Cervantes e incluso cervantized la novela David Simple, rubricada por su hermana Sarah. Hammond explica que:

Mid-century reinscriptions of Don Quixote were important, I suggest, since they enabled a form of fiction that, while it still qualified as «serious» on the criteria that were evolving in the period, nevertheless provided the readerly satisfactions that-as readers from Samuel Johnson to Sir Walter Scott have testified-it appeared to be Richardson's express purpose to deny ${ }^{51}$.

Como se apuntaba al comienzo de este ensayo, la aportación de Ronald Paulson ha ofrecido una novísima perspectiva en el estudio del cervantismo del siglo XVIII inglés. Paulson discute las obras de los novelistas ya mencionados, y sitúa a Don Quixote en el contexto político y artístico de la época, revelando así su influencia en pintores como Hogarth o John Vanderbank y en poetas como Addison, Steel, Shaftesbury o Milton.

A la luz de los esfuerzos por demostrar que el Quijote ha sido el texto extranjero más influyente a lo largo de toda la historia de la literatura inglesa, las negativas de un sector de la filología inglesa no pueden sino antojarse un ejercicio de proteccionismo nacional. Si, como apuntaba Walter Scott ${ }^{52}$, Tom Jones es la primera novela en lengua inglesa y Henry Fielding el padre de la novela británica, a tenor de las conclusiones a que ha llegado la crítica con respecto al cervantismo de la obra de Fielding ${ }^{53}$, a

\footnotetext{
50 J. A. G. ARDILA, «Cervantes y la quixotic fiction: el hibridismo genérico», Cervantes, XXI, 2 (2001), 43-66.

${ }^{51}$ Brean HAMMOND, op. cit., 261.

52 Walter ScotT, Lives of the Novelists (Londres: J. M. Dent, 1820), 46-70,

53 Además de los anteriormente referidos: Gerhard BUCK, «Written in Imitation of the Manner of Cervantes», Germanische-Romanische Monatsschrift, 29 (1941), 53-61; Emile PoNs, «Fielding, Swift and Cervantes. De Don Quichotte in England à Joseph Andrews», Studia Neophilologica, 15 (1942-43), 305-333; Homer GLODBERG, «The Interpolated Stories in Joseph Andrews or 'The History of the World in General' Satirically Revised», Modern Philology, 63 (1963), 295-310; Allen R. PENNER, «Fielding's Adaptation of Cervantes' Knight and Squire. The Character of Joseph», Revue de Littérature Comparée, 41 (1967), 508-514; Leon L. DRISKELL, «Interpolated Tales in
} 
Cervantes podría aplicarse el apelativo de antecedente más directo de la novela inglesa. Éste es el parecer de Harry Levin, quien, siguiendo a Albert Thibaudet, designa por quixotic principle «the direct line of Cervantes' impact as the basic process he discovered and its wider employment» ${ }^{54}$. Levin concuerda con Thibaudel en que el Quijote es «le roman des roman» así como «le roman contre les romans» ${ }^{55}$ y entiende que el process que Cervantes descubriera e inaugurara no consiste sino en la elaboración de la dicotomía romance-novela, en especial a través de las figuras de Don Quijote y Sancho. El quixotic principle podría aplicarse, acaso y como demuestra el ensayo de Levin, ad infinitum, por cuanto la literatura, como cualquier otro arte, es sempiterna innovación, y su naturaleza, proteica ${ }^{56}$.

La admiración que los intelectuales británicos profesaron a la obra de Cervantes derivó en una obnubilada pasión por las letras castellanas. Sirva de ejemplo el caso de Susanna Rowson: exaltada defensora de la supremacía protestante de Gran Bretaña y los Estados Unidos, como se refleja en sus textos educativos, Rowson vituperó siempre la política exterior hispánica, sin dudar, empero, en alabar la figura de Cervantes. Rowson reconoció la influencia de Cervantes en el prólogo de su Slaves in Algiers e incluso tomó prestados el género, tema y título del Viaje del Parnaso para su Trip to Parnassus. No es extraño, por tanto, que su afición por la obra de Cervantes llevase a Rowson, enemiga acérrima del catolicismo español, a degustar de los otros frutos del Siglo de Oro español que los traductores le habían proporcionado, y que se inspirase en Celestina para redactar el que sería reconocido en el siglo Xx como el primer best-seller de la litera-

Joseph Andrews and Don Quixote: The Dramatic Method», South Atlantic Bulletin, 33 (1968), 5-8; Douglas BROOKS, «The Interpolated Tales in Joseph Andrews again», Modern Philology, 65 (1968), 208-213; Lee J. GREENE, «Fielding Gypsy Episode and Sancho Panza's Governorship», South Atlantic Bulletin, 39 (1974), 117-121; Juventino CAMINERO, «Joseph Andrews y Don Quijote de la Mancha: dos castos varones», Letras de Deusto, 9 (1979), 95-129; Rita GNUTZMANN, «Don Quixote in England de Henry Fielding con relación al Don Quijote de Cervantes», Anales Cervantinos, 22 (1984), 77 101; Santiago ACOSTA, «El influjo del Quijote en Joseph Andrews», Revista Canaria de Estudios Ingleses, 11 (1985), 69-80; Luisa ANTÓN-PACHECO, Sátira y parodia en el Quijote y Joseph Andrews (Madrid: Universidad Complutense, 1989); Isolina BALLESTEROS, «La presencia del Quijote de Cervantes en Joseph Andrews de Fielding», Anales Cervantinos, 27 (1989), 215-224;

${ }^{54}$ Harry LEvIN, «The Quixotic Principle: Cervantes and Other Novelists», Harvard English Studies, I (1970), 45-66, 58.

${ }_{55}$ Albert THIBAUDET, Le Liseur des romans (París, 1925), xv.

56 Noción muy similar a la que traza Wayne C. BоOTH, «The Self-conscious Narrator in Comic Fiction Before Tristram Shandy», PMLA, LXVII, 2 (1952), 163-185, 165: «It has long been customary in literary histories to say that Sterne was influenced by Cervantes ... But surely just as striking ... is the fact that Don Quixote is really the first important novel using the self-conscious narrator. Indeed Cervantes developed the device to a point not reached by any other comic novelist until well into the eighteenth century». 
tura norteamericana: Charlotte Temple ${ }^{57}$. Siquiera la presencia de Celesti$n a$ en la Inglaterra de los siglos XVII y XVIII ha quedado constatada por una multiplicidad de estudios ${ }^{58}$, además de las versiones, Charlotte Temple es la única novela que parece haberse inspirado en la obra de Rojas.

Si las circunstancias de las letras inglesas del Setecientos se veían reflejadas especialmente en el Quijote, las históricas se correspondían con las características de la novela picaresca española. Sin embargo, la crítica angloparlante se ha mostrado escéptica a la hora de reconocer la huella de la picaresca española en la británica. Ian Watt ${ }^{59}$, en su apreciado Rise of the Novel, fue voz pionera en repudiar cualquier tipo de influencia española en la picaresque novel. Para Watt, los orígenes de la picaresca británica deben buscarse en los beggar-books, y, tomando como ejemplo Moll Flanders, sostiene sus argumentos contra la picaresca española sobre una serie de teorías que atentan contra las conclusiones alcanzadas por la crítica hispanista ${ }^{60}$. Con apotegmas del tipo de que el pícaro español no es un delincuente y de que la novela picaresca se halla exenta de toda significación religiosa, Watt demostró desconocer la novela picaresca española -0 , al menos, la crítica en torno a ella-. A Watt lo ha secundado la inmensa mayoría de la crítica ${ }^{61}$ con contadas excepciones, entre las que se

${ }^{57}$ La discusión acerca de A Trip to Parnassus y Charlotte Temple puede hallarse en J. A. G. ARDILA, «La herencia británica de Fernando de Rojas: Mlle. La Rue, o la celestina en Charlotte Temple», Hispanófila, 128 (2000), 13-35.

58 Véanse H. D. PURCELL, "The Celestina and the Interlude of Calisto and Melebea», Bulletin of Hispanic Studies, XLIV (1967), 1-15, además de los artículos y las introducciones a las traducciones inglesas que tratan el tema: G. J. BRAULT, «English Translations of the Celestina in the Sixteenth Century», Hispanic Review, XXVIII (1960), 301-312; James Fitzmaurice-Kelly, «Introduction, en F. de Rojas, Celestina (op. cit.), Guadalupe Martínez Lacalle (op. cit.) y Dorothy Sherman Severin, «Introduction», en F. DE ROJAS, Celestina (op. cit.).

${ }^{59}$ Ian WATT, «Defoe as Novelist: Moll Flanders», en The Rise of the Novel: Studies in Defoe, Richardson and Fielding (op. cit.), 104-147.

${ }^{60}$ Un detallado escolio de los argumentos de Watt en este sentido se encuentra en J. A. G. ARDILA, «Revisión de las posturas anglófilas en torno a la picaresque fiction: notas comparativistas desde la orilla del hispanismo», Anuario de Estudios Filológicos, XXIII (2000), 173-186.

${ }^{61}$ Inter alia: P. G. BOUCE, The Novels of Tobias Smollett (Londres: Longman, 1976); Robert ALTER, «A Bourgeois Picaroon», en Rogue's Progress: Studies in the Picaresque Novel (Cambridge: Cambridge University Press, 1964), 35-57; James WALTON, «The Romance of Gentility: Defoe's heroes and Heroines», en Eric ROTHSTEIN (ed.), Literary Monographs (Madison: University of Wisconsin Press, 1971), IV, 91-135; Richard BJORNSON, The Picaresque Hero in European Fiction (Madison: University of Wisconsin Press, 1977): Alice G. FREDMAN, «The Picaresque in Decline: Smollett's First Novel», en John H. MIDDENDORF (ed.), English Writers of the Eighteenth Century (Nueva York y Londres: Columbia University Press, 1979), 189-207; Jerry C. BEASLEY, «Roderick Random: The Picaresque Transformed», College Literature, 5 (1979), 211-220; Maximiliam E. NovaK, Realism, Myth, and History in Defoe's Fiction (Lincoln y Londres: The University of Nebraska Press, 1983). 
cuentan, Robert Giddens, Alexander Parker, Stuart Miller, Robert Spector, Gustav Ungerer y J.A.G. Ardila ${ }^{62}$. Efectivamente, y aunque los trabajos de estos filólogos demuestren el peso de la picaresca española en la picaresca británica, la novela picaresca más aplaudida por los ingleses fue la francesa Gil Blas de Lesage. Las traducciones del Lazarillo y del Guzmán fueron reimpresas en varias ediciones a lo largo de los siglos XVII y XVIII ${ }^{63}$, así como las del Buscón o la Pícara Justina. Para ejemplificar el poder de la picaresca española baste con recordar el título que James Mabbe dio a su traducción del Guzmán: The Rogue, o el pícaro, porque Guzmán fue en Inglaterra, al igual que en España, el prototipo del pícaro.

El influjo del Guzmán es conspicuo en las letras inglesas del Seiscientos. Para Gustav Ungerer el interés por la picaresca española se debe a las razones políticas de los royalists (o monárquicos) que se oponían a la república puritana de Cromwell. En el 'Guzmán hallaron los partidarios de la monarquía la antítesis del estricto sentir puritano y es Guzmán, sugiere Ungerer, la fuente de cuantos highwaymen (o saltadores de caminos) y panders (o medianeros) proliferaron en la prosa inglesa del XVII. Por ello, señala Ungerer, "The congeniality between the Spanish rogues and the English criminals points to the close and steady intellectual relationship negotiated between Spanish picaresque fiction and English criminal biography» ${ }^{64}$. Y, a pesar de que durante la Restauración el gusto por las novelas picarescas parece decaer, los autores que se habían propuesto experimentar con la prosa hasta producir novela en lengua inglesa hallaron en la picaresca española, al igual que en el Quijote, la forma novelística que ansiaban.

David Skilton ensayó una clasificación de la novela picaresca inglesa estructurándola en (1) biografías de criminales y (2) novelas picarescas de Defoe $^{65}$. En tan somera apreciación, Skilton vindica lo que continúa inci-

${ }^{62}$ Robert GIDDINS, The Tradition of Smollett (Londres: Methuen, 1967); Alexander A. PARKER, Los picaros en la literatura: la novela picaresca en Europa (1599-1753) (Madrid: Gredos, 1970); Stuart MILlER, The Picaresque Novel (Cleveland, 1967); Robert D. SPECTOR, Tobias George Smollett, Updated Edition (Boston: Hall, 1989); J. A. G. ARDILA, «La tradición picaresca española en Inglaterra» (op. cit.); J. A. G. ARDILA, «Revisión de las posturas anglófilas en torno a la picaresque fiction: notas comparativistas desde la orilla del hispanismo» (op. cit.); Gustav UNGERER, «English Criminal Biography and Guzmán de Alfarache's Fall from Rogue to Highwayman, Pander and Astrologer», Bulletin of Hispanic Studies, Liverpool, LXXVI (1999), 189-197.

${ }^{63}$ Vid. Dale Randall, op. cit. o George B. PARKS y Ruth Z. TEMPle (eds.), The Literatures of the World in English Translation. A Bibliography (Nueva York: Frederick Ungar Publishing Co., 1970).

${ }^{64}$ Gustav UNGERER, «English Criminal Biography and Guzmán de Alfarache's Fall from Rogue to highwayman, Pander and Astrologer» (op. cit.), 193.

${ }^{65}$ David SKILTON, The English Novel, Defoe to the Victorians (Londres: David and Charles, 1977), 34. 
tando a la discordia, la agrupación de toda la beggar literature y las criminal biographies dentro de la denominación de novela picaresca. En «La tradición picaresca española en Inglaterra», Ardila ${ }^{66}$ ha acometido un ejemplo de la picaresca inglesa del único modo que acaso sea lícito - y pragmático-: el análisis en la prosa inglesa de todas y cada una de las características que la crítica especializada en novela picaresca española ha reconocido como fundamentales en este género - salvando, naturalmente, las disensiones entre sus críticos-. Las obvias restricciones obligaron a Ardila a limitarse a Moll Flanders, una de las novelas en discordia; sin embargo, tal proceso analítico es necesario de modo que se delimite la novela picaresca inglesa en cuanto participe de las característica de los modelos originales.

A pesar de que amplios sectores de la filología inglesa porfíen en resistirse a reconocer los orígenes españoles de la novela británica del siglo XVIII, los estudios publicados en el último decenio inauguran el reconocimiento - que parece definitivo- de la crítica hispanista y auguran un cambio de pareceres en el siglo que se abre. Los esfuerzos de muchos, no obstante, pueden muy bien antojarse estériles si quienes ostentan el reconocimiento de eminencias en la generalidad de la novela británica no reciclan sus argumentos. Resulta imperativo insistir en que no sólo es perentorio que los estudios filológicos y los manuales didácticos reconozcan las evidencias que se les presentan, es preciso, asimismo, afinar la vieja terminología de modo que no suene tan rancia: los términos quixotic fiction/ novel y picaresque fiction/novel, que han viciado el entendimiento de la novela británica del XVIII. La propuesta no es, en absoluto, original, Alexander Parker y Edward Riley ya apuntaron sendos preliminares al juicio semántico que reclamaban para estos términos.

Edward Riley advierte:

En la primera mitad del siglo XVIII, el Quijote pasa a ser admirado especialmente por su ironía y su sátira. Se situó a Cervantes junto a Luciano y Rabelais, y se consideró peculiarmente efectivo el «aire grave y serio» de su ironía. El libro se entendía como una épica burlesca en prosa y como una parodia donde el Caballero era una caricatura del héroe. Las palabras «quijotada» y «quijotesco» entraron en uso con un significado despectivo ${ }^{67}$.

Si bien hoy día es notorio que la influencia del Quijote en la novela británica no se limitó a la mera recreación de su protagonista, el término quixotic fiction sigue empleándose a fin de designar la prosa del XVIII cuyos personajes sufren un trastorno mental que les convierte en figuras paródicas $-\mathrm{y}$ cómicas-. David Skilton presenta la quixotic fiction como aquella que

66 J. A. G. ARDILA, «La tradición picaresca española en Inglaterra», op. cit.

${ }^{67}$ Edward C. RILEY, Introducción al Quijote (Barcelona: Editorial Crítica, 1990), 226. 
tiene por protagonista «the excentric good-doer» ${ }^{6}$, v.g. Sir Launcelot Greaves. La expresión quixotic fiction es, como apunta Riley, empleada erróneamente en inglés: por quixotic fiction debía entenderse, como es lógico, toda ficción que participe de uno u otro modo de los objetivos y las características del Quijote. Sin embargo, dentro de esta denominación se ha agrupado el conjunto de novelas que anuncian en su título la participación de un personaje de psicología análoga a la de Don Quijote. Estas novelas son, por lo general, de una calidad literaria acaso desmerecedora, y con las excepciones de Sir Launcelot Greaves, The Female Quixote, Northanger Abbey y The Spiritual Quixote de Richard Graves, la enjundia del resto no ha alentado el interés de la crítica moderna. Como consecuencia de este empleo discriminatorio de la expresión quixotic fiction, el mundo angloparlante se ha convencido que el Quijote sólo sirvió de modelo a estos creadores de excéntricos personajes que bautizaban como Quixote ${ }^{69}$.

Mas lo cierto es que el Quijote moldeó los cuños de diversas índoles de novela. Hammond presenta cinco ${ }^{70}$ bajo la denominación de Cervantic fiction. Paulson señala una Quixote fiction $^{71}$, que es paródica; pero prefiere referirse al Quijote como el Cervantean model ${ }^{72}$ y discierne Quixotic characters ${ }^{73}$ -aquellos que sufren una quixotic madness ${ }^{74}$ - de Cervantean narrative ${ }^{75}$. En efecto, los novelistas británicos se fijaron en seis aspectos temáticos y estilísticos del Quijote - como han demostrado las antedichas referencias bibliográficas-: (1) su carácter satírico y paródico; (2) su comicidad; (3) su estructura narratológica; (4) su hibridismo genérico; (5) ciertas situaciones; y (6) personajes que imitaron, fundamentalmente Don Quijote, Sancho y Dulcinea.

\footnotetext{
${ }^{68}$ David SKILTON, op. cit., 34.

69 Así las cosas, el reconocimiento a la obra cervantina se ha introducido en la misma lengua inglesa, v.g. en la expresión «to tilt at wind mills» o el uso generalizado del adjetivo quixotic significando excéntrico (no necesariamente good-doer, v.g. en el uso más reciente que he localizado, en una carta al director de The Daily Telegraph, 45467 [19-8-01]).

${ }^{70}$ Brean HAMMOND, op. cit., 262: «(i) the typical narrative structuring of specific incidents; (ii) the Quixote and Sancho Panza character-types; (iii) the collision between a set of 'spiritual' or 'idealistic' values derived from a body of literature and the earthiness of quotidian incidents; (iv) dominant themes of madness and the law, and, (v) epistemological questions raised on the levels of narrative content». Para Paulson, quien contempla el Quijote en relación no sólo de la novelística sino de las corrientes artísticas en general, existen cuatro: «I see the efect of Don Quixote centered on four general areas of contested notions - the 'madness' of imagination, the cruelty of the laughter of ridicule, the problematizing of the beautiful..., and, in many ways the most volatile issue, the extension of the idea of 'madness' in the face of empirical reason into the area of religious doctrine» (op. cit.), xiii-xiv.

${ }^{71}$ Roland PAULSON, op. cit., 10.

72 Ibid. xii.

${ }^{73}$ Ibid. 59.

74 Ibid. 69

${ }^{75}$ Ibid. 59.
} 
Convendría, en consecuencia, aclarar los términos, en especial por cuanto el único que se ha empleado recurridamente es quixotic fiction. Se podría admitir el empleo de quixotic fiction para agrupar al tipo de narrativa cómico-paródica que presenta un personaje de locura quijotesca, lo que requeriría establecer las diferencias entre ésta y una cervantic o cervantean fiction que englobe las novelas que participen de las otras cinco características. Lo cierto es que la obra de Cervantes no se reduce al Quijote y que sus otros libros gozaron asimismo de gran aclamación. (A Trip to Parnassus de Rowson no es quixotic, porque no recoge la influencia del Quijote, pudiendo ser sólo cervantean). Se plantea de este modo la distinción, ya vislumbrada por Harry Levin, entre adaptación e imitación, o «imitators» y «emulators» ${ }^{76}$, de la obra de Cervantes, fundamentalmente del Quijote. El término quixotic fiction, según lo ha empleado la crítica angloparlante, designaba las imitaciones del Quijote, v.g. The Female Quixote, The Political Quixot, The Spiritual Quixote, etc. ${ }^{77}$. A tenor de la presencia de las otras cinco características en la novelística inglesa del $\mathrm{XVIII}$, es de justicia designar a aquellas novelas que de éstas participen -y que sean, por tanto, obra de emuladores- cervantean fiction, en grado que puedan distinguirse de la quixotic fiction, género éste ya delimitado.

En los párrafos introductorios a su «Spanish Picaresque Novel in French Translation Prior to 1715», Peter Spier distingue la obra de Lesage de otras picarescas francesas, indicando que en la trilogie picaresque de Lesage «one finds the clearest 'debt' to the Spanish tradition» ${ }^{78}$. En inglés, picaresque fiction es toda novela cuya acción se compone de una sucesión de episodios protagonizados por un mismo personaje protagonista — quien, las más de las veces, no es un pícaro-. La aclamada English Literature de Anthony Burgess, reimpresa en numerosas ocasiones desde los años cincuenta, presenta la picaresque fiction explicando que:
With Fielding one is inclined to use the term picaresque (from the Spanish picaro, meaning 'rogue'), a term originally applicable only to novels in which the leading character is a rogue (such as the popular Gil Blas by Le Sage, published between 1715 and 1735). It is a term which lends itself to description of all the novels in which the bulk of the action takes place on the road, on a journey, and in which eccentric and low-life characters appear. Don Quixote is, in some ways, picaresque ${ }^{79}$.

\footnotetext{
${ }^{76}$ Harry LEVIN, op. cit., 47.

${ }^{77}$ Así Ardila tratara de reclamar por medio de los títulos de su serie de ensayos «Cervantes y la quixotic fiction» el influjo que Cervantes tubo en novelas que son adaptaciones en lugar de imitaciones.

78 Peter SPIER, «The Spanish Picaresque Novel in French Translation Prior to 1715», New Comparison, 15 (1993), 15-20, 16.

79 Antony BURGESS, English Literature, 23 ed. (Harlow: Longman, 1996), 159. Cf. Frederick Olds BISSELL, Fielding's Theory of the Novel (Nueva York: Cooper Square Publishers, 1969), 2: «The picaresque novel is an indirect attack on the novels of chivalry, realistic, cynical in tone, and glorifying the vulgar rogue instead of the idealized, saintly knight».
} 
El problema es análogo al planteado por la quixotic fiction. Alexander Parker ${ }^{80}$ cuestionó la semántica de picaresque fiction en Los pícaros en la literatura. Parker recuerda que pícaro en el inglés del siglo XVIII era rogue, y que la voz castellana dio lugar a la inglesa picaroon. Arguye a partir de ahí que rogue no es utilizado en el inglés del siglo $\mathrm{xx}, \mathrm{y}$ que, salvando las dificultades diacrónicas, los individuos que en la actualidad cometen el tipo de delitos que otrora cometieran los pícaros reciben en inglés el apelativo delinquents: por ello, Parker titula el original de su obra Literature and the Delinquent ${ }^{81}$, que después se tradujo al castellano como Los pícaros y la literatura.

Lo cierto es que la semántica contemporánea de pícaro no se corresponde con la del Siglo de Oro, y que el pícaro de entonces sería hoy, también, un delincuente, lo que invalida, o al menos cuestiona, la hermenéutica de Parker. Si se aceptan las teorías de Watt y de sus seguidores, según las cuales ninguna novela inglesa participa de los cánones picarescos españoles, carece de sentido considerar una picaresque fiction, sino que habría de procurarse otra fórmula con que designar adecuadamente las novelas cuyo protagonista es un rogue (v.g. roguery fiction) o cuya estructura siga una sucesión episódica. Las conclusiones a que han llegado Parker, Miller, Spector o Ardila obligan a apuntar lo inapropiado del término inglés: toda vez que existe en la literatura británica un tipo de novela que tiene por protagonista un pícaro y que coincide con la tipología genérica de la picaresca española, el calco lingüístico de que resulta picaresque fiction debería responder a la semántica del original. La sucesión de episodios que ahora se designa como picaresque fiction es uno de los aspectos que el Quijote introdujo en Gran Bretaña: las novelas de Fielding son tildadas de picaresque por organizar su trama en una sucesión episódica, pero esta estructura la toma Fielding del Quijote, por lo que su obra es cervantean fiction, diferente a la picaresque fiction de otras novelas como Moll Flanders.

\footnotetext{
${ }^{80}$ Alexander A. PARKER, «Prólogo a la traducción española», en Los pícaros en la literatura. La novela picaresca en España y Europa (1599-1753) (op. cit.), 7-31.

${ }^{81}$ Alexander A. PARKER, Literature and the Delinquent: The Picaresque Novel in Spain and Europe (1599-1753) (Edimburgo: Edinburgh University Press, 1967).
} 